\title{
The increasing threat of silver-resistance in clinical isolates from wounds and burns
}

\author{
Alaa El-Dien MS Hosny' \\ Salwa A Rasmy' \\ Dina S Aboul-Magd ${ }^{2}$ \\ Mona T Kashef' \\ Zeinab E El-Bazza ${ }^{2}$ \\ 'Microbiology and Immunology \\ Department, Faculty of Pharmacy, Cairo \\ University, Cairo, Egypt; ${ }^{2}$ Drug Radiation \\ Research Department, National Center \\ for Radiation Research and Technology, \\ Atomic Energy Authority, Cairo, Egypt
}

Correspondence: Mona T Kashef Department of Microbiology and Immunology, Faculty of Pharmacy, Cairo University, Kasr El-Eini St, Cairo II562, Egypt

Tel +2 0223639307

$\mathrm{Fax}+20223628426$

Email mona.kashef@pharma.cu.edu.eg
This article was published in the following Dove Press journal:

Infection and Drug Resistance

\begin{abstract}
Purpose: The widespread use of silver-containing compounds has led to emergence of silver-resistant bacteria. Few studies are available on the detectability of plasmid-mediated silver-resistance in developing countries. Therefore, we aimed to detect silver-resistance in isolates from wounds and burns, and to genetically characterize plasmid-mediated silver-
\end{abstract} resistance genes (sil genes).

Methods: One hundred and fifty clinical isolates were obtained from burns and wounds. They were identified using the suitable Analytical Profile Index and MicroScan identification systems. Their antimicrobial susceptibility was tested by the disk diffusion and broth microdilution methods. Their silver nitrate $\left(\mathrm{AgNO}_{3}\right)$ minimum inhibitory concentration (MIC) was determined using the broth macrodilution method. The presence of different sil genes on plasmids extracted from silver-resistant isolates and the replicon types of the extracted plasmids were investigated using polymerase chain reaction (PCR). The ability of these plasmids to impart silver-resistance was tested by transformation.

Results: All except two isolates were multidrug-resistant. Nineteen silver-resistant bacterial isolates (12.6\%) were detected; with $\mathrm{AgNO}_{3} \mathrm{MIC} \geq 512 \mu \mathrm{g} / \mathrm{mL}$. They were identified as Klebsiella pneumoniae $(\mathrm{n}=7)$, Staphylococcus aureus $(\mathrm{n}=4)$, Escherichia coli $(\mathrm{n}=2)$, Enterobacter cloacae $(\mathrm{n}=2)$, Pseudomonas aeruginosa $(\mathrm{n}=2)$ and Acinetobacter baumannii $(\mathrm{n}=2)$. PCR revealed the presence of different sil genes on the extracted plasmids. Plasmid transformation resulted in the transfer of silver-resistance to the resulting transformants. The extracted plasmids had different replicon types.

Conclusion: Plasmid-mediated silver-resistance was detected for the first time, in clinical $P$. aeruginosa, A. baumannii and $S$. aureus isolates; in addition to its detection in K. pneumoniae, E. coli and Enterobacter cloacae. Therefore, strict monitoring on the use of silver compounds in medical settings is required; with implementation of an approved standardized method for silver-resistance detection.

Keywords: multidrug-resistance, plasmid-mediated, replicon type, sil genes

\section{Introduction}

The silver cation $\left(\mathrm{Ag}^{+}\right)$has been employed long ago as an antimicrobial agent (eg, $\mathrm{AgNO}_{3}$ solution and silver sulfadiazine cream), for its microbicidal properties, minimum toxicity to human cells and therapeutic activity; especially in the prevention and treatment of burns and chronic wounds infections. ${ }^{1}$

Silver ions cause respiration inhibition, membrane damage and destruction of the proton motive force in sensitive organisms; through their interaction with thiol groups present in membrane proteins or enzymes and consequently the respiratory chain enzymes. ${ }^{2}$ It can also generate reactive oxygen species that interfere with DNA replication ${ }^{3}$ and increase membrane permeability. ${ }^{4}$ 
Silver-impregnated dressings and antimicrobial coatings are used in infection management and stimulation of wound healing. ${ }^{5,6}$ Also, silver is used as a component in dental amalgam and silver-impregnated medical devices, such as catheters and heart valves. ${ }^{7}$ The widespread and uncontrolled use of silver may result in increasing the rate of bacterial resistance to silver-containing compounds where silver-resistant bacteria are as problematic as antibiotic-resistant ones. ${ }^{8}$

Acquired silver-resistance can be of endogenous (mutational) or exogenous (horizontally acquired) origin. Endogenous resistance to silver in Gram-negative bacteria can arise from derepression of the chromosomal Cus system and loss of outer membrane porins. ${ }^{9,10}$ Also, derepression of the expression of silver-resistance genes (sil genes), integrated into Escherichia coli chromosome, has been reported to result in silver-resistance after stepwise adaptation in laboratory. ${ }^{11}$ Staehlin and colleagues ${ }^{12}$ have described a heavy metal homeostasis/resistance island, named as Copper homeostasis and silver resistance island (CHASRI), which was assembled and dispersed within members of Enterobacteriaceae family. Recently, CHASRI was found to be equally distributed in the plasmids and chromosomes of Enterobacteriaceae and was able to provide silver-resistance after mutation in $\mathrm{CusS}$ and/or silS genes of the CHASRI island. ${ }^{13}$

Exogenous silver-resistance was documented to be due to acquisition plasmid-encoded sil system. ${ }^{14,15}$ The first encountered exogenous (horizontally acquired) silver-resistance was detected in a bacterial strain of Salmonella enterica serovar Typhimurium that caused an outbreak on a burns ward in 1975; causing the death of three patients. ${ }^{16}$ Later, this resistance phenotype was detected in other bacterial species. ${ }^{17,18}$ The first described plasmid was isolated from this Salmonella strain and named pMG101. The silver-resistance determinant comprises nine Open Reading Frames (ORFs) defining three transcriptional units (silE,

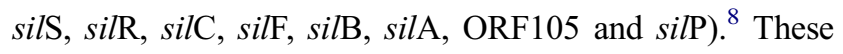
acquired silver-resistance genes are usually located on plasmids of the incompatibility group HI2 (IncHI2). ${ }^{19}$

Silver-resistance, whether endogenous or exogenous mediated, arises mainly from restriction of intracellular accumulation of silver. silE is a small periplasmic silver-binding protein that binds silver specifically at the cell surface; presenting the first line of resistance against silver toxicity. Also, there is a two-component silver-responsive transcriptional regulation system; silRS. This system controls the expression of a silver efflux ATPase; silP, the tripartite
silCBA silver effluxer and silF, which is periplasmic silver chaperone. ${ }^{8,20}$ Endogenous silver-resistance, due to porin loss and over expression of Cus system that causes silver efflux, also limits the accumulation of silver inside the cell. ${ }^{14}$

Detection of exogenously acquired silver-resistance in K. pneumoniae and Enterobacter spp. isolates is highly worrisome where only few therapeutic options will be available for treatment of these bugs; if any. The available data on exogenously acquired silver-resistance and the distribution of sil genes among hospital pathogens, in developing countries; including Egypt, are rare. Therefore, the aim of this study was to detect silver-resistance and the associated resistance to other antibiotics as well as to detect and characterize plasmid-encoded sil genes; in different clinical isolates from wounds and burns infections.

\section{Materials and methods}

\section{Analysis of silver-resistance genes in different bacterial species}

sil genes present in the publically available genomes, of different bacterial species, were retrieved from Patricbrc web resources (https://www.patricbrc.org). ${ }^{21}$ The status of retrieved sil genes, whether chromosomal or plasmid encoded, was confirmed by searching their accession numbers on NCBI nucleotide database.

\section{Microorganisms}

One hundred and fifty bacterial isolates from wounds $(n=102)$ and burns $(n=48)$ were collected between October 2015 and April 2016 from the Central Laboratories, ElDemerdash Hospital, Ain Shams University, Cairo, Egypt. All wound and burn sepsis samples, collected during this period, were sent to laboratories for routine diagnosis. They were collected using sterile cotton swabs and transferred to the laboratories in Cary-Blair transport system. In the laboratory, they were inoculated aseptically onto blood and MacConkey agar plates (Oxoid Ltd., Hampshire, UK) and incubated at $35-37^{\circ} \mathrm{C}$ for $24-48 \mathrm{hrs}$. The isolated colonies were identified using the suitable Analytical Profile Index (Biomeriéux Inc., France) and MicroScan (Beckman Coulter, USA) identification systems; following manufacturers' instructions. Escherichia coli TOP10 was used as a recipient strain in the transformation experiments.

\section{Ethics approval and informed consent}

This study was approved by the ethical committee of the Faculty of Pharmacy, Cairo University, Cairo, Egypt 
(approval number: MI 1537). An oral informed consent was obtained from the patients since the samples were collected during routine diagnosis and no special interventions were made for the research purpose.

\section{Antimicrobial susceptibility testing of the collected isolates}

The antimicrobial susceptibility testing of the isolated bacterial species was determined by Kirby-Bauer disk diffusion method $^{22}$ except against vancomycin and polymyxin B where antimicrobial susceptibility was determined by the broth microdilution method. ${ }^{23}$ The selection of the antimicrobial agents was based on the type of the organism being tested, and the results were interpreted following the Clinical and Laboratory Standards Institute (CLSI) and European Committee on Antimicrobial susceptibility Testing (EUCAST) interpretive criteria. ${ }^{24,25}$ The antibiotic disks included in the study were gentamicin $10 \mu \mathrm{g}$, piperacillin/ tazobactam $100 \mu \mathrm{g} / 10 \mu \mathrm{g}$, imipenem $10 \mu \mathrm{g}$, meropenem $10 \mu \mathrm{g}$, cefazolin $30 \mu \mathrm{g}$, ceftazidime $30 \mu \mathrm{g}$, cefepime $30 \mu \mathrm{g}$, cefoxitin $30 \mu \mathrm{g}$, ciprofloxacin $5 \mu \mathrm{g}$, sulfamethoxazole/trimethoprim $23.75 \mu \mathrm{g} / 1.25 \mu \mathrm{g}$, tigecycline $15 \mu \mathrm{g}$, aztreonam $30 \mu \mathrm{g}$, chloramphenicol $30 \mu \mathrm{g}$, doxycycline $30 \mu \mathrm{g}$, fusidic acid $10 \mu \mathrm{g}$, clindamycin $2 \mu \mathrm{g}$, erythromycin $15 \mu \mathrm{g}$, linezolid $30 \mu \mathrm{g}$ and quinupristin/dalfopristin $15 \mu \mathrm{g}$ (All from Oxoid Ltd., Hampshire, UK).

\section{Determination of $\mathrm{AgNO}_{3}$ minimum inhibitory concentration (MIC)}

The susceptibility of different isolates to $\mathrm{AgNO}_{3}$ (SigmaAldrich, USA) was evaluated by MIC determination using broth macrodilution method. ${ }^{23}$ Two-fold serial dilutions of $\mathrm{AgNO}_{3}$ were prepared, using deionized water, to give a concentration range from 4 to $512 \mu \mathrm{g} / \mathrm{mL}$. Isolates with $\mathrm{MIC}$ of $\geq 512 \mu \mathrm{g} / \mathrm{mL}$, against $\mathrm{AgNO}_{3}$, were classified as silverresistant. $^{26}$

\section{Detection of different sil genes}

Genomic DNA was extracted from all isolates by the boiling method. ${ }^{27}$ The extracted DNA was tested for the presence of $s i l \mathrm{P}, s i \mathrm{~B}, s i l \mathrm{~F}, s i l \mathrm{E}, s i l \mathrm{~A}, s i l \mathrm{CBA}$ and $s i l \mathrm{RS}$ genes by the polymerase chain reaction (PCR) as suggested by Woods et al; ${ }^{17}$ with minor modifications in primers' sequences to increase the specificity of the reaction (Table 1). Also, reaction temperatures were optimized using gradient PCR. The identity of the positive amplicons, from each reaction, was confirmed by sequencing and isolates that were confirmed to possess the tested genes were used as positive controls for subsequent reactions.

PCR products were visualized on $1.5 \%$ agarose gel (Axygen Biosciences, CA, USA) by electrophoresis using 100-bp ladder (Invitrogen, ThermoFisher Scientific, MA, USA). Randomly selected PCR products, of the expected size, were purified with QIAquick PCR Purification Kit (Qiagen, Crawley, UK) and sequenced by $\mathrm{ABI}^{\mathrm{TM}} 3500$ Genetic Analyzer DNA sequencer (Applied Biosystems, Foster City, CA). Similarity searches for the nucleotide sequences were performed with BLASTN program (http:// www.ncbi.nlm.nih.gov/blast) using default settings.

\section{Determination of the origin of sil genes}

Plasmids were extracted from all isolates, that were positive for any of the tested sil genes, using a GeneJET Plasmid Miniprep kit (Invitrogen, ThermoFisher Scientific, MA, USA); following the manufacturer's instructions. The extracted plasmids were tested for the presence of different sil genes; as described previously.

\section{Confirmation of the ability of extracted plasmids to impart silver-resistance phenotype}

The ability of the extracted plasmids to confer silver-resistance was tested by transformation into E. coli TOP10.

Table I Primers used for sil genes detection with the corresponding annealing temperatures and the expected amplicon size

\begin{tabular}{|l|l|l|l|l|}
\hline Gene & Forward primer & Reverse primer & Annealing temperature ( ${ }^{\circ}$ C) & Amplicon size (bp) \\
\hline silE & aggggaaacggtctgacttc & atatccatgagcgggtcaac & 52 & 221 \\
silB & caaagaacagcgcgtgatta & gctcagacattgctggcata & 52 & 233 \\
silP & cctgggtttacagcgtcatt & atggcacctgaggtttgttc & 52 & 175 \\
silF & cgatatgaatgctgccagtg & attgccctgctgaataaacg & 52 & 229 \\
silA & cttgagcatgccaacaagaa & ctgccagtacaggaaccat & 54 & 162 \\
silRS & gacggcaatcgcaatcagatt & gtggaggatactgcgagagc & 54 & 192 \\
silCBA & cgggaaacgctgaaaaattatgaa & gtacgttcccagcaccagtt & 54 & 189 \\
\hline
\end{tabular}


Briefly, the extracted plasmids from each silver-resistant bacterial isolate were electroporated into electrocompetent E. coli TOP10 cells using a Gene Pulser electroporator (Gene MicroPulser ${ }^{\mathrm{TM}}$ Electroporation System, Bio-Rad, USA); according to the manufacturer's instructions. Transformants were selected on LB agar (Merk Millipore, Germany) plates supplemented with $64 \mu \mathrm{g} / \mathrm{mL} \mathrm{AgNO}_{3}$ (The $\mathrm{AgNO}_{3}$ MIC of E. coli TOP10 was $32 \mu \mathrm{g} / \mathrm{mL}$ ). Transformants were tested for their antimicrobial susceptibility, to different antibiotics, using Kirby-Bauer disk diffusion method and broth microdilution method; as mentioned before. Their $\mathrm{AgNO}_{3}$ MICs were determined by broth macrodilution method, as described previously.

\section{PCR-based plasmid replicon typing}

Plasmid replicon typing, of the plasmids extracted from the silver-resistant isolates, was performed according to Johnson et al. $^{28}$

\section{Results}

\section{Bioinformatics analysis of silver-resistance genes}

sil genes were detected in 400 different bacterial genomes present in the publically available genomes' sector of Patric resources. The plasmid or chromosomal location, of the retrieved genomes containing sil genes, was determined. Twenty one genomes were confirmed to have plasmidencoded sil genes. These genomes were from Klebsiella pneumoniae (seven strains), Escherichia coli (nine strains) and Enterobacter cloacae (five strains). All plasmid-encoded sil cassettes contained the nine open reading frames described by Gupta et al. ${ }^{8}$ No sil genes were detectable in the publically available genomes of Acinetobacter baumannii or Staphylococcus aureus.

\section{Identification of bacterial isolates from burns and wounds}

Bacterial isolates collected from wounds and burns were identified as $K$. pneumoniae $(\mathrm{n}=32)$, E. coli $(\mathrm{n}=22)$, P. aeruginosa $(\mathrm{n}=21)$, Enterobacter cloacae $(\mathrm{n}=\mathrm{six}$ isolates), Klebsiella aerogenes $(\mathrm{n}=\mathrm{two}$ isolates), A. baumannii $(\mathrm{n}=14)$, Proteus mirabilis $(\mathrm{n}=15)$ and $S$. aureus $(\mathrm{n}=38)$.

\section{Antimicrobial and silver susceptibility patterns of the collected isolates}

The antibiogram of the isolated bacterial species revealed that all except two isolates were multidrug-resistant
"MDR" according to the definition of Magiorakos et al. ${ }^{29}$ MDR is defined as non-susceptibility to at least one agent in three or more antimicrobial categories. ${ }^{29}$ E. coli TOP10 was susceptible to all tested antimicrobials. The results of identification of isolated bacterial species and their antibiogram are given in Table S1.

Of the 150 tested isolates, nineteen bacterial isolates were silver-resistant; with a MIC $\geq 512 \mu \mathrm{g} / \mathrm{mL}$; against $\mathrm{AgNO}_{3}$. They were identified as $\mathrm{K}$. pneumoniae (seven isolates), E. coli (two isolates), Enterobacter cloacae (two isolates), $P$. aeruginosa (two isolates), A. baumannii (two isolates) and $S$. aureus (four isolates). None of the tested Klebsiella aerogenes or Proteus mirabilis was resistant to $\mathrm{AgNO}_{3}$. The silver-susceptible bacterial isolates had MIC range of 32-128 $\mu \mathrm{g} / \mathrm{mL}$; against $\mathrm{AgNO}_{3}$.

\section{Detection of the silver-resistance genes}

All isolates were tested for the presence of different sil genes using seven primer pairs capable of detecting the eight identified silver-resistance genes. Silver-susceptible isolates were negative for all tested sil genes; however, all silver-resistant isolates recorded positive results for at least three of the tested sil genes. All tested sil genes were detectable in six out of the 19 silver-resistant isolates (three $K$. pneumoniae isolates, one E.coli isolate, one $A$. baumannii isolate and one $S$. aureus isolate). Other isolates were positive only for some but not all of the tested sil genes. Table 2 describes the detectability of different sil genes in each of the tested isolates. The obtained sequences, of the selected PCR amplicons, were deposited in GenBank under accession numbers MH229478 to MH229484. E. coli TOP10 was negative for all tested sil genes.

\section{Origin of silver-resistance genes and plasmid replicon typing}

All detected sil genes were found to be encoded on the extracted plasmids. To further confirm the location of the detected sil genes on the extracted plasmids and not on chromosomal contaminant, the DNA was extracted from the plasmid bands separated on the agarose gel and tested for the presence of different sil genes. The results confirmed the plasmid location of sil genes. Transformation of the plasmids extracted from silver-resistant isolates into E. coli TOP10 resulted in 19 bacterial transformants with the same silverresistance level as that of the original isolates $\left(\mathrm{AgNO}_{3} \mathrm{MIC}\right.$ $\geq 512 \mu \mathrm{g} / \mathrm{mL}$ ). The results of the antimicrobial susceptibility testing of the transformants revealed susceptibility to all of the 
Table 2 Detectability of sil genes in silver-resistant isolates and the obtained transformants

\begin{tabular}{|c|c|c|c|c|c|c|c|}
\hline Bacterial species & silRS & silE & silCBA & silB & silA & silP & silF \\
\hline $176 \mathrm{~K}$ & + & - & + & + & + & + & + \\
\hline $176 K_{T}$ & + & - & + & + & + & + & + \\
\hline 197K & + & - & + & + & + & + & + \\
\hline $197 K_{T}$ & + & - & + & + & + & + & + \\
\hline $199 K$ & + & + & + & + & + & + & + \\
\hline $199 K_{T}$ & + & + & + & + & + & + & + \\
\hline $215 K$ & + & + & + & + & + & + & + \\
\hline $215 K_{T}$ & + & + & + & + & + & + & + \\
\hline $465 K$ & + & - & + & + & + & + & + \\
\hline $465 K_{T}$ & + & - & + & + & + & + & + \\
\hline $724 K$ & + & - & + & + & + & + & + \\
\hline $724 K_{T}$ & + & - & + & + & + & + & + \\
\hline $793 K$ & + & + & + & + & + & + & + \\
\hline $793 K_{T}$ & + & + & + & + & + & + & + \\
\hline 205E & + & + & + & + & + & + & + \\
\hline $205 E_{T}$ & + & + & + & + & + & + & + \\
\hline $263 E$ & + & + & - & + & + & + & - \\
\hline $263 E_{T}$ & + & - & - & + & + & + & - \\
\hline 285En & + & - & - & + & + & - & - \\
\hline $285 E n_{T}$ & + & - & - & + & + & - & - \\
\hline 367En & + & - & - & + & + & - & - \\
\hline $367 E n_{T}$ & + & - & - & + & + & - & - \\
\hline $314 P$ & + & - & - & - & + & + & - \\
\hline $3 \mid 4 P_{T}$ & + & - & - & - & + & - & - \\
\hline $646 P$ & + & + & - & - & + & + & - \\
\hline $646 P_{T}$ & + & + & - & - & + & - & - \\
\hline $407 A c$ & + & + & + & + & + & + & + \\
\hline $407 A c_{T}$ & + & + & + & + & + & + & + \\
\hline $457 A c$ & - & + & - & + & + & + & + \\
\hline $457 A c_{T}$ & - & + & - & + & + & + & + \\
\hline 4475 & + & + & + & + & + & + & + \\
\hline $447 S_{T}$ & + & + & + & + & + & + & + \\
\hline $579 S$ & - & - & + & + & + & + & + \\
\hline $579 S_{T}$ & - & - & + & + & + & + & + \\
\hline 5865 & - & - & - & + & - & + & + \\
\hline $586 S_{T}$ & - & - & - & + & - & + & + \\
\hline 6015 & - & + & - & - & + & + & - \\
\hline $601 S_{T}$ & - & + & - & - & + & + & - \\
\hline
\end{tabular}

Notes: Dark shaded cells indicate the genes that were not detectable in the some of the resulting transformants. Abbreviation: $\mathrm{T}$, the corresponding transformant.

tested antimicrobial agents. They exhibited resistance pattern similar to that of the E. coli TOP10, against these agents. The resulting transformants possessed the same sil genes as that in the original isolates, except three transformants where transformant $263 E_{T}$ was negative for silE and transformants $314 P_{T}$ and $646 P_{T}$ were negative for silP (Table 2). 
Plasmid replicon typing was performed on the extracted plasmids. Most of the plasmids belonged to the incompatibility groups IncX (four isolates; $215 K, 465 K$, $447 S$ and $586 S$ ), IncHI1 (three isolates; $199 K, 724 K$ and $457 A c$ ), IncN (three isolates; 205E, 285En and 367En), IncI1 (three isolates; $798 \mathrm{~K}, 314 \mathrm{P}$ and $646 P$ ) and $\mathrm{IncB} / \mathrm{O}$ (two isolates; $579 S$ and $601 S$ ). In addition, one plasmid belonged to each of the incompatibility groups IncFrep (176K), IncFIC (197K), IncP (263E) and IncA/C (407Ac).
The plan of work and the obtained results are summarized in Figure 1.

\section{Discussion}

Silver has been considered as an alternative to commonly used antimicrobials due to the widespread antimicrobial resistance. ${ }^{30}$ However, appearance of plasmid-mediated silver-resistance presented an alarm where silver-resistance can limit the effectiveness of silver-based

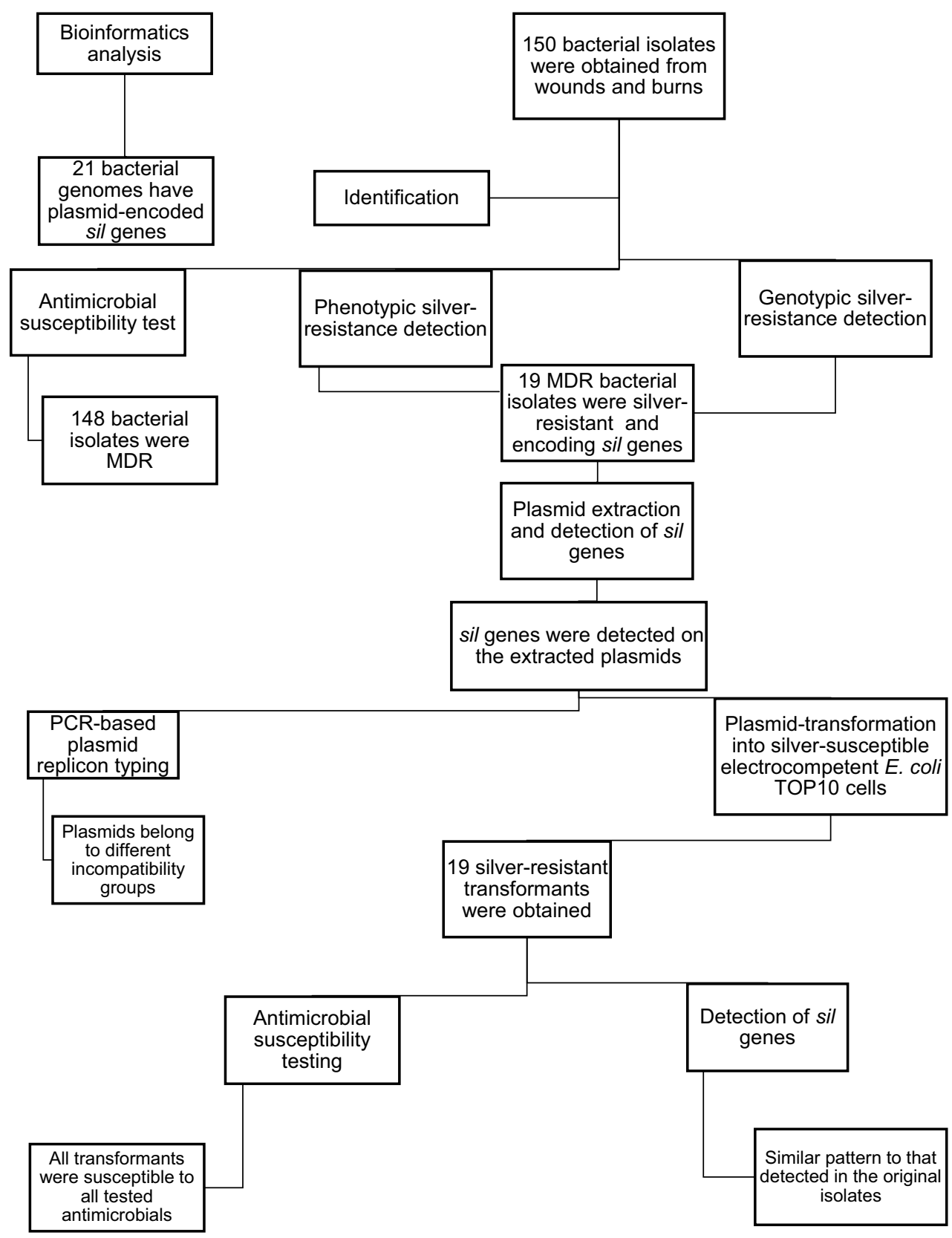

Figure I Scheme of the work process with the obtained results.

Abbreviations: MDR, multidrug-resistant; sil genes, silver-resistance genes. 
antimicrobials in the future. Only few studies addressed this threat; especially in developing countries.

In this study, 150 clinical isolates, from wounds and burns, were collected. Most of the isolated species were Gram-negative bacteria (75\%), which comes in agreement with previous studies about the pattern of bacterial types colonizing wounds and burns. ${ }^{31,32}$ S. aureus was the predominantly detected organism (26\%) followed by K. pneumoniae $(21 \%)$. Some previous studies have reported $S$. aureus as the predominant isolate from wounds. ${ }^{33,34}$ On the other hand, Srinivasan et $\mathrm{al}^{35}$ and Forson et $\mathrm{al}^{36}$ detected $K$. pneumoniae and $P$. aeruginosa as the predominant organisms, respectively. This difference, in predominance, may have resulted from variation in the applied treatment practices.

It was difficult to compare our silver-resistance rate to that published in most of available studies; where different cutoff values were used for defining silver-resistant isolates. ${ }^{14,37}$ Since no universal standard MIC breakpoint, for silver-resistance, is available, we hereby take this opportunity to highlight the urgent need for defining the standard MIC breakpoint for silver-resistance. Only two studies were concerned with silver-resistance rates, in clinical isolates, and used the same MIC breakpoint as that we used here. We were able to detect silver-resistance in $12.6 \%$ of the collected isolates. Similarly, Sütterlin and coworkers $^{38}$ detected phenotypic silver-resistance in six out of 56 bacterial isolates (11\%). Also, in another study, Sütterlin and coworkers ${ }^{26}$ recorded phenotypic silverresistance in $13 \%$ of Enterobacter spp., and 3\% of Klebsiella spp. out of 752 blood stream isolates.

What worsens the condition is that all of our isolated silver-resistant bacteria were MDR. This is not surprising where most of our silver-resistant isolates belonged to ESKAPE pathogens (Enterococcus faecium, Staphylococcus aureus, Klebsiella pneumoniae, Acinetobacter baumannii, Pseudomonas aeruginosa and Enterobacter spp.) which are known with their MDR phenotype. ${ }^{39}$ They were also detectable in E. coli where MDR phenotypes, in different clones of $E$. coli, isolated from extraintestinal infection, has been reported previously. ${ }^{40}$ However, it is highly worrisome regarding the limited therapeutic options available; if any. ${ }^{41}$

Silver-resistance was detected in K. pneumoniae (seven isolates), E. coli (two isolates), P. aeruginosa (two isolates), A. baumannii (two isolates), Enterobacter cloacae (two isolates) and $S$. aureus (four isolates). The detection of silverresistance among different Gram-negative bacteria belonging to Enterobacteriaceae family is common. ${ }^{38}$ However, we are reporting for the first time the detection of silver-resistant $P$. aeruginosa, A. baumannii and $S$. aureus clinical isolates. To our knowledge, only two studies were concerned with silverresistance in $S$. aureus where Sütterlin and colleagues ${ }^{38}$ recorded their $\mathrm{AgNO}_{3} \mathrm{MIC}$ to be in the range of $16-32 \mu \mathrm{g} /$ $\mathrm{mL}$ (sensitive range according to the used MIC breakpoint). Also, in a study carried by Randall and coworkers, ${ }^{42}$ no evidence was found for silver-resistance in 876 clinical staphylococcal isolates, nor could any reduction in silver-susceptibility be selected upon extended exposure (42 days) of S. aureus to silver in vitro.

The cause for this variation, in the detectability of silver-resistance, is not clear. Our isolates were collected from wound and burn patients that were treated with silver sulfadiazine $(1 \%)$ cream during the period of samples collection. The same was reported by Randall et $\mathrm{al}^{42}$ about the use of silver compounds during the period of collection of their burn and diabetic foot ulcer $S$. aureus isolates (They were at least 230 isolates). Silver-resistance in our $S$. aureus isolates may have been resulted from the regular use of silver sulfadiazine cream in Egyptian facilities which may have selected for resistant isolates where different protocols may be applied in other areas; limiting the spread of resistance.

We searched the publically available genomes, of Patric resources, for plasmid-mediated sil genes; to check the possibility of their presence as part of sequenced plasmids. This was done to avoid any possibility of missing sil genes that may be present in species other than those available in literature. The detectability of plasmid-mediated sil genes, among our collection of both Gram-negative and positive isolates, was different from that available in Patric resources. In publically available genomes, plasmid-mediated sil genes were detectable in K. pneumoniae, E. coli and Enterobacter cloacae only. However, here we were able to detect these genes also in A. baumannii, $P$. aeruginosa and $S$. aureus. Previous studies reported the detection of plasmid-mediated sil genes only in clinical isolates from Enterobacteriaceae family as Salmonella enterica serovar Typhimurium isolated from burns ward, ${ }^{8}$ E. coli, ${ }^{19}$ Enterobacter cloacae and $K$. pneumoniae. ${ }^{14}$

Presence of plasmid-mediated sil genes, in isolates from wounds and burns, is highly dangerous. This is because of the possibility of plasmid transfer between different bacterial species colonizing the wound; where chronic wounds are usually colonized with a collection of different bacteria. They, therefore, provide an ultimate environment for plasmids to travel among contaminating 
strains; especially that biofilms are becoming significant in this area. ${ }^{43}$

In our study, and in accordance with the detectability of different sil genes on plasmids from the publically available genomes in Patric resources, six isolates were positive for all tested sil genes. However, the remaining isolates missed one or more genes. Similar findings, regarding the absence of some sil genes, were reported previously. ${ }^{14,38,44}$ In our study, isolates belonging to Enterobacteriaceae family mostly lacked silE, silCBA and silF genes. This is different from the gene possession described by Gupta et $\mathrm{al}^{19}$ where only $s i l \mathrm{E}$ and silP genes were sometimes missed in Enterobacteriaceae members. No records are available about the sil genes possession in other bacterial species.

This difference in sil genes detectability may have resulted from the molecular method employed in gene detection; where all retrieved genes from the database were from a fully sequenced plasmid. In our study, as well as in others, the genes were detected mainly by PCR; where variation in gene sequences may have caused the failure of amplification by the used primers. Minor sequence variation $(\approx 4 \%)$ was previously recorded in different sil genes. ${ }^{10,19}$

The possession of sil genes is not enough to account for phenotypic resistance to silver as derepression of Sil system is required for expression of silver-resistance phenotype. ${ }^{10}$ Therefore, the ability of the extracted plasmids to impart silver-resistance was confirmed by transformation; where all the resulting transformants had the same level of silver-resistance. In addition, they have the same sil genes profile except three transformants. The reason underlying this variation in gene profiles is unclear.

Several cellular mechanisms can also account for silver-resistance, in addition to the acquisition of derepressed plasmid-encoded sil genes; as mutations in chromosomal Cus system together with the loss of outer membrane porins. ${ }^{9,10}$ However, it is unlikely to be responsible for silver-resistance in all our transformants; as mutations causing silver-resistance were not detectable, in laboratory testing, even after several passages in suprainhibitory concentrations of silver nitrate. ${ }^{10}$

Plasmid replicon typing, of the extracted plasmids, was performed using the method of Johnson et $\mathrm{al}^{28}$ for detection of incompatibility groups of plasmids from Enterobacteriaceae family. We applied this method to plasmids extracted from different bacterial species, whether Enterobacteriaceae or not, based on the history of the detectability of plasmid-mediated silver-resistance, in clinical isolates from members of Enterobacteriaceae family only, as discussed previously.

All extracted plasmids were typable and carried only one of the tested replicon types; even those from organisms not belonging to Enterobacteriaceae family. This indicated that all of these plasmids may have originated from organisms belonging to the family Enterobacteriaceae. The transfer of plasmids from Enterobacteriaceae members to other Gramnegative or Gram-positive bacteria; such as $P$. aeruginosa, $A$. baumannii and $S$. aureus, has been reported previously. ${ }^{45-47}$

Silver-resistance genes are known to be carried only on plasmids of IncHI group. ${ }^{15,19}$ However, our plasmidmediated sil genes were detected on plasmids of different replicon types, as IncFrep, IncFIC, IncHI1, IncX, IncI1, IncN, IncP, IncA/C and IncB/O. This may have resulted from the integration of sil cassette into different plasmid types, mediated by $\mathrm{Tn}-7$ transposition, as described by Randall et al. ${ }^{10}$

It was surprising that none of the obtained transformants gained resistance to any of the tested antimicrobials; to which the original isolates were resistant. This indicated that the antimicrobial resistance determinants, in our collected isolates, were not encoded on the same plasmid together with the detected silver-resistance genes which is quite opposite to the MDR phenotype associated with the plasmid pMG101. ${ }^{48}$

Further study is still required to investigate different mechanisms underlying this MDR phenotype and its possible linkage to silver-resistance. The results of plasmid replicon typing confirmed the presence of only one replicon type in each extracted plasmid preparation. However, only replicons from Enterobacteriaceae family were tested as indicated previously; where plasmids from other species may be present and go undetectable by Enterobacteriaceae plasmid replicon typing. Antimicrobial resistance determinants may have been encoded on large plasmids that are not transformed efficiently by electroporation. ${ }^{49}$ Also, the mechanisms underlying MDR phenotype may not be plasmid encoded; as in case of mutations causing efflux pumps overexpression or loss of outer membrane porins or may be encoded by chromosomal genes.

This study is alarming regarding the spread of phenotypic silver-resistance and sil genes in species where they were not detectable before. However, several questions are still required to be answered, as few numbers of isolates were studied in each species. So, other studies are required to address the detectability of silver-resistance in large number of isolates from each species together with their 
genetic background and clonal dissemination. In addition, nearly all of our isolated strains were MDR so it was difficult to draw a solid conclusion about the association between silver-resistance and MDR.

\section{Conclusion}

We are reporting here, for the first time, the detectability of silver-resistance and plasmid-mediated sil genes in different types of clinical isolates ( $P$. aeruginosa, A. baumannii and $S$. aureus). This is highly worrisome in terms of resistance spread; especially within the poly-microbial-infected wounds and burns, and the limited therapeutic options where all silver-resistant isolates were MDR. Therefore, a careful monitoring on the use of silver-containing antimicrobial agents is highly required with the development of an approved standardized method for the detection of silverresistance.

\section{Disclosure}

The authors declare that the research was conducted in the absence of any commercial or financial relationships that could be construed as a potential conflict of interest in regard to this work.

\section{References}

1. Atiyeh BS, Costagliola M, Hayek SN, Dibo SA. Effect of silver on burn wound infection control and healing: review of the literature. Burns. 2007;33(2):139-148. doi:10.1016/j.burns.2006.06.010

2. Holt KB, Bard AJ. Interaction of silver (I) ions with the respiratory chain of Escherichia coli: an electrochemical and scanning electrochemical microscopy study of the antimicrobial mechanism of micromolar $\mathrm{Ag}^{+}$. Biochem. 2005;44(39):13214-13223. doi:10.1021/bi0508542

3. Park HJ, Kim JY, Kim J, et al. Silver-ion-mediated reactive oxygen species generation affecting bactericidal activity. Water Res. 2009;43 (4):1027-1032. doi:10.1016/j.watres.2008.12.002

4. Morones-Ramirez JR, Winkler JA, Spina CS, Collins JJ. Silver enhances antibiotic activity against Gram-negative bacteria. Sci Transl Med. 2013;5(190):190ra81. doi:10.1126/scitranslmed.3006276

5. Chopra I. The increasing use of silver-based products as antimicrobial agents: a useful development or a cause for concern? J Antimicrob Chemother. 2007;59(4):587-590. doi:10.1093/jac/dkm006

6. Mijnendonckx K, Leys N, Mahillon J, Silver S, Van Houdt R. Antimicrobial silver: uses, toxicity and potential for resistance. Biometals. 2013;26(4):609-621. doi:10.1007/s10534-013-9645-Z

7. Silver S. Bacterial silver resistance: molecular biology and uses and misuses of silver compounds. FEMS Microbiol Rev. 2003;27(23):341-353. doi:10.1016/S0168-6445(03)00047-0

8. Gupta A, Kazuaki M, Lo JF, Silver S. Molecular basis for resistance to silver cations in Salmonella Nat Med. 1999;5(2):183-188. doi: $10.1038 / 5545$

9. Lok CN, Ho CM, Chen R, Tam PK, Chiu JF, Che CM. Proteomic identification of the Cus system as a major determinant of constitutive Escherichia coli silver resistance of chromosomal origin. J Proteome Res. 2008;7(6):2351-2356. doi:10.1021/pr700646b
10. Randall CP, Gupta A, Jackson N, Busse D, O’Neill AJ. Silver resistance in Gram-negative bacteria: a dissection of endogenous and exogenous mechanisms. J Antimicrob Chemother. 2015;70(4):1036-1046.

11. Blanco Massani M, Klumpp J, Widmer M, et al. Chromosomal Sil system contributes to silver resistance in E. coli ATCC 8739. Biometals. 2018;31(6):1101-1114. doi:10.1007/s10534-018-0143-1

12. Staehlin BM, Gibbons JG, Rokas A, O'Halloran TV, Slot JC. Evolution of a heavy metal homeostasis/resistance island reflects increasing copper stress in enterobacteria. Genome Biol Evol. 2016;8(3):811-826. doi:10.1093/gbe/evw031

13. Hanczvikkel A, Füzi M, Ungvári E, Tóth Á. Transmissible silver resistance readily evolves in high-risk clone isolates of Klebsiella pneumoniae. Acta Microbiol Immunol Hung. 2018;65(3):387-403. doi:10.1556/030.65.2018.031

14. Finley PJ, Norton R, Austin C, Mitchell A, Zank S, Durham P. Unprecedented silver resistance in clinically isolated Enterobacteriaceae: major implications for burn and wound management. Antimicrob Agents Chemother. 2015;59(8):4734-4741. doi:10.1128/AAC.00026-15

15. Fang L, Li X, Li L, Liao X, Sun J, Liu Y. Co-spread of metal and antibiotic resistance within ST3-IncHI2 plasmids from E. coli isolates of food-producing animals. Sci Rep. 2016;6:25312-25319. doi:10.1038/srep25312

16. McHugh GL, Moellering RC, Hopkins CC, Swartz MN. Salmonella typhimurium resistant to silver nitrate, chloramphenicol, and ampicillin. Lancet. 1975;305(7901):235-240. doi:10.1016/S0140-6736(75)91138-1

17. Woods EJ, Cochrane CA, Percival SL. Prevalence of silver resistance genes in bacteria isolated from human and horse wounds. Vet Microbiol. 2009;138(3-4):325-329. doi:10.1016/j.vetmic.2009.03.023

18. Sütterlin S, Edquist P, Sandegren L, et al. Silver resistance genes are overrepresented among Escherichia coli isolates with CTX-M production. App Env Microbiol. 2014;80(22):6863-6869. doi:10.1128/ AEM.01803-14

19. Gupta A, Phung LT, Taylor DE, Silver S. Diversity of silver resistance genes in IncH incompatibility group plasmids. Microbiol. 2001;147:3393-3402. doi:10.1099/00221287-147-12-3393

20. Mergeay M, Monchy S, Vallaeys T, et al. Ralstonia metallidurans, a bacterium specifically adapted to toxic metals: towards a catalogue of metal-responsive genes. FEMS Microbiol Rev. 2003;27(2-3):385410. doi:10.1016/S0168-6445(03)00045-7

21. Wattam AR, Davis JJ, Assaf R, et al. Improvements to PATRIC, the allbacterial bioinformatics database and analysis resource center. Nucleic Acids Res. 2017;45(D1):D535-D542. doi:10.1093/nar/gkw1017

22. Clinical and Laboratory Standards Institute. Performance Standards for Antimicrobial Disk Susceptibility Tests. $11^{\text {th }}$. CLSI document M02-A11. Wayne (PA): CLSI; 2012a.

23. Clinical and Laboratory Standards Institute. Methods for Dilution Antimicrobial Susceptibility Tests for Bacteria that Grow Aerobically. $9^{\text {th }}$. CLSI document M07-A9. Wayne (PA): CLSI; 2012b.

24. Clinical and Laboratory Standards Institute. Performance Standards for Antimicrobial Susceptibility Testing. 27 $7^{\text {th }}$. CLSI supplement M100. Wayne (PA): CLSI; 2017.

25. The European Committee on Antimicrobial Susceptibility Testing. Breakpoint Tables for Interpretation of MICs and Zone Diameters. Version 7.1. EUCAST; 2017. Available from: http://www.eucast.org. Accessed June 12, 2019.

26. Sütterlin S, Dahlö M, Tellgren-Roth C, Schaal W, Melhus A. High frequency of silver resistance genes in invasive isolates belonging to genera Enterobacter and Klebsiella. J Hosp Infect. 2017;96(3):256261. doi:10.1016/j.jhin.2017.04.017

27. Queipo-Ortuňo MI, Colmenero JDD, Macias M, Bravo MJ, Morata P. Preparation of bacterial DNA template by boiling and effect of immunoglobulin $\mathrm{G}$ as an inhibitor in real-time PCR for serum samples from patients with brucellosis. Clin Vaccine Immunol. 2008;15 (2):293-296. doi:10.1128/CVI.00270-07 
28. Johnson TJ, Wannemuehler YM, Johnson SJ, et al. Plasmid replicon typing of commensal and pathogenic Escherichia coli isolates. Appl Environ Microbiol. 2007;73(6):1976-1983. doi:10.1128/AEM.02171-06

29. Magiorakos AP, Srinivasan A, Carey RB, et al. Multidrug-resistant, extensively drug-resistant and pandrug-resistant bacteria: an international expert proposal for interim standard definitions for acquired resistance. Clin Microbiol Infect. 2012;18(3):268-281. doi:10.1111/ j.1469-0691.2011.03570.x

30. Melaiye A, Youngs WJ. Silver and its application as antimicrobial agent. Expert Opin Ther Pat. 2005;15(2):125-130. doi:10.1517/ 13543776.15.2.125

31. Mama M, Abdissa A, Sewunet T. Antimicrobial susceptibility pattern of bacterial isolates from wound infection and their sensitivity to alternative topical agents at Jimma University specialized hospital, South-West Ethiopia. Ann Clin Microbiol Antimicrob. 2014;13 (14):14-23. doi:10.1186/1476-0711-13-14

32. Patil P, Joshi S, Bharadwaj R. Aerobic bacterial infections in a burns unit of Sassoon general hospital, Pune. Int J Healthcare Biomed Res. 2015;3(3):106-112.

33. Nwachukwu NC, Orji FA, Okike UM. Antibiotic susceptibility patterns of bacterial isolates from surgical wounds in Abia State University teaching hospital (ABSUTH), Aba-nigeria. Res $\mathrm{J}$ Med Sci. 2009;4(2):575-579.

34. Mohammed A, Seid ME, Gebrecherkos T, Tiruneh M, Moges F. Bacterial isolates and their antimicrobial susceptibility patterns of wound infections among inpatients and outpatients attending the University of Gondar referral hospital, Northwest Ethiopia. Int $J$ Microbiol. 2017;2017:1-10. doi:10.1155/2017/8953829

35. Srinivasan S, Varma AM, Patil A, Saldanha J. Bacteriology of the burn wound at the Bai Jerbai Wadia hospital for children, Mumbai, India-a 13-year study, part I - bacteriological profile. Indian J Plast Surg. 2009;42(2):213-218. doi:10.4103/0970-0358.59284

36. Forson OA, Ayanke E, Olu-Taiwo M, Pappoe-Ashong PJ, AyehKumi PF. Bacterial infections in burn wound patients at a tertiary teaching hospital in Accra, Ghana. Ann Burns Fire Disasters. 2017;30(2):116-120.

37. Ip M, Lui SL, Poon VK, Lung I, Burd A. Antimicrobial activities of silver dressings: an in vitro comparison. J Med Microbiol. 2006;55:59-63. doi:10.1099/jmm.0.46124-0

38. Sütterlin S, Tano E, Bergsten A, Tallberg AB, Melhus A. Effects of silver-based wound dressings on the bacterial flora in chronic leg ulcers and its susceptibility in vitro to silver. Acta Derm Venereol. 2012;92(1):34-39. doi:10.2340/00015555-1170
39. Santajit S, Indrawattana N. Mechanisms of antimicrobial resistance in ESKAPE pathogens. Biomed Res Int. 2016;2016:2475067. doi:10.1155/2016/2475067

40. Hussain A, Ranjan A, Nandanwar N, Babbar A, Jadhav S, Ahmed N. Genotypic and phenotypic profiles of Escherichia coli isolates belonging to clinical sequence type 131 (ST131), clinical non-ST131, and fecal non-ST131 lineages from India. Antimicrob Agents Chemother. 2014;58 (12):7240-7249. doi:10.1128/AAC.03320-14

41. Boucher HW, Talbot GH, Bradley JS, et al. Bad bugs, no drugs: no ESKAPE! An update from the Infectious Diseases Society of America. Clin Infect Dis. 2009;48(1):1-12. doi:10.1086/595011

42. Randall CP, Oyama LB, Bostock JM, Chopra I, O’Neill AJ. The silver cation $\left(\mathrm{Ag}^{+}\right)$: antistaphylococcal activity, mode of action and resistance studies. J Antimicrob Chemother. 2013;68(1):131-138. doi:10.1093/jac/dks372

43. Percival SL, Woods EJ, Nutekpor M, Bowler P, Radford A, Cochrane C. Prevalence of silver resistance in bacteria isolated from diabetic foot ulcers and efficacy of silver containing wound dressings. Ostomy Wound Manage. 2008;54(3):30-40.

44. Loh JV, Percival SL, Woods EJ, Williams NJ, Cochrane CA. Silver resistance in MRSA isolated from wound and nasal sources in humans and animals. Int Wound J. 2009;6(1):32-38. doi:10.1111/ j.1742-481X.2008.00563.x

45. Courvalin P. Transfer of antibiotic resistance genes between grampositive and gram-negative bacteria. Antimicrob Agents Chemother. 1994;38(7):1447-1451. doi:10.1128/aac.38.7.1447

46. Demanèche S, Kay E, Gourbière F, Simonet P. Natural transformation of Pseudomonas fluorescens and Agrobacterium tumefaciens in soil. Appl Environ Microbiol. 2001;67(6):2617-2621. doi:10.1128/ AEM.67.6.2617-2621.2001

47. Salto IP, Tejerizo GT, Wibberg D, Pühler A, Schlüter A, Pistorio M. Comparative genomic analysis of Acinetobacter spp. plasmids originating from clinical settings and environmental habitats. Sci Rep. 2018;8:7783-7794. doi:10.1038/s41598-018-26180-3

48. Silver S, Phung le T, Silver G. Silver as biocides in burn and wound dressings and bacterial resistance to silver compounds. $J$ Ind Microbiol Biotechnol. 2006;33(7):627-634. doi:10.1007/s10295-006-0139-7

49. Sheng Y, Mancino V, Birren B. Transformation of Escherichia coli with large DNA molecules by electroporation. Nucleic Acids Res. 1995;23(11):1990-1996. doi:10.1093/nar/23.11.1990 


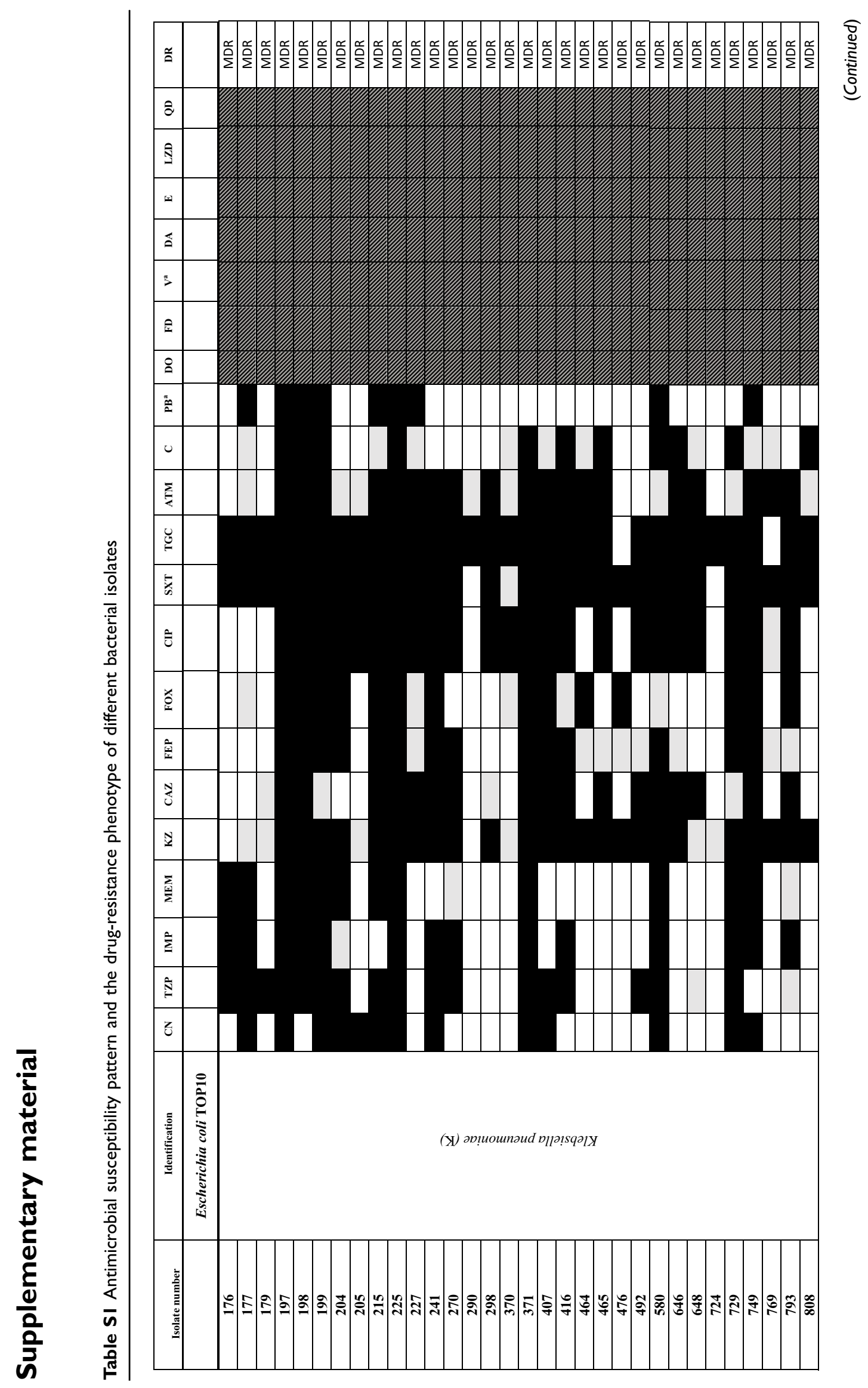




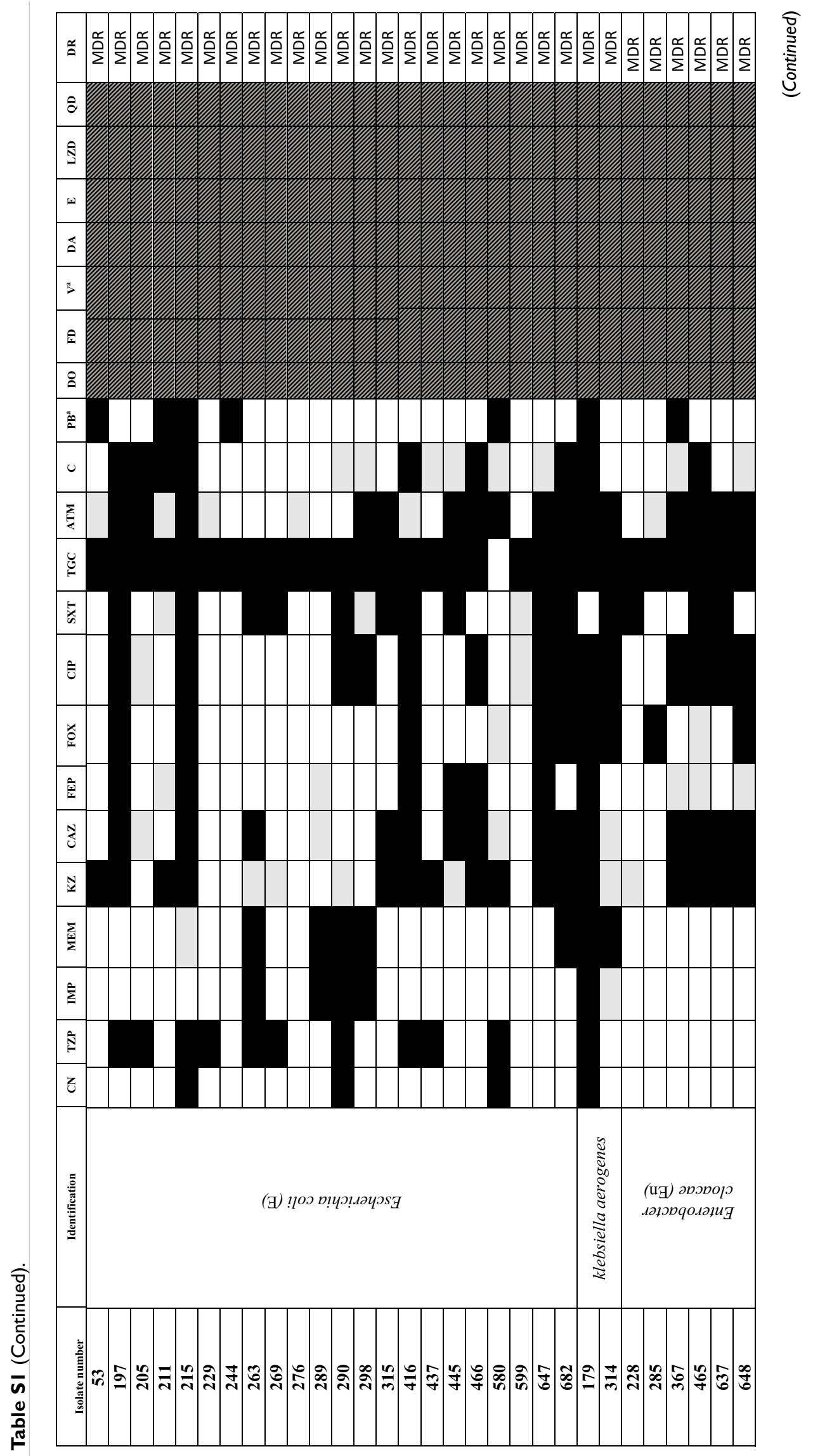




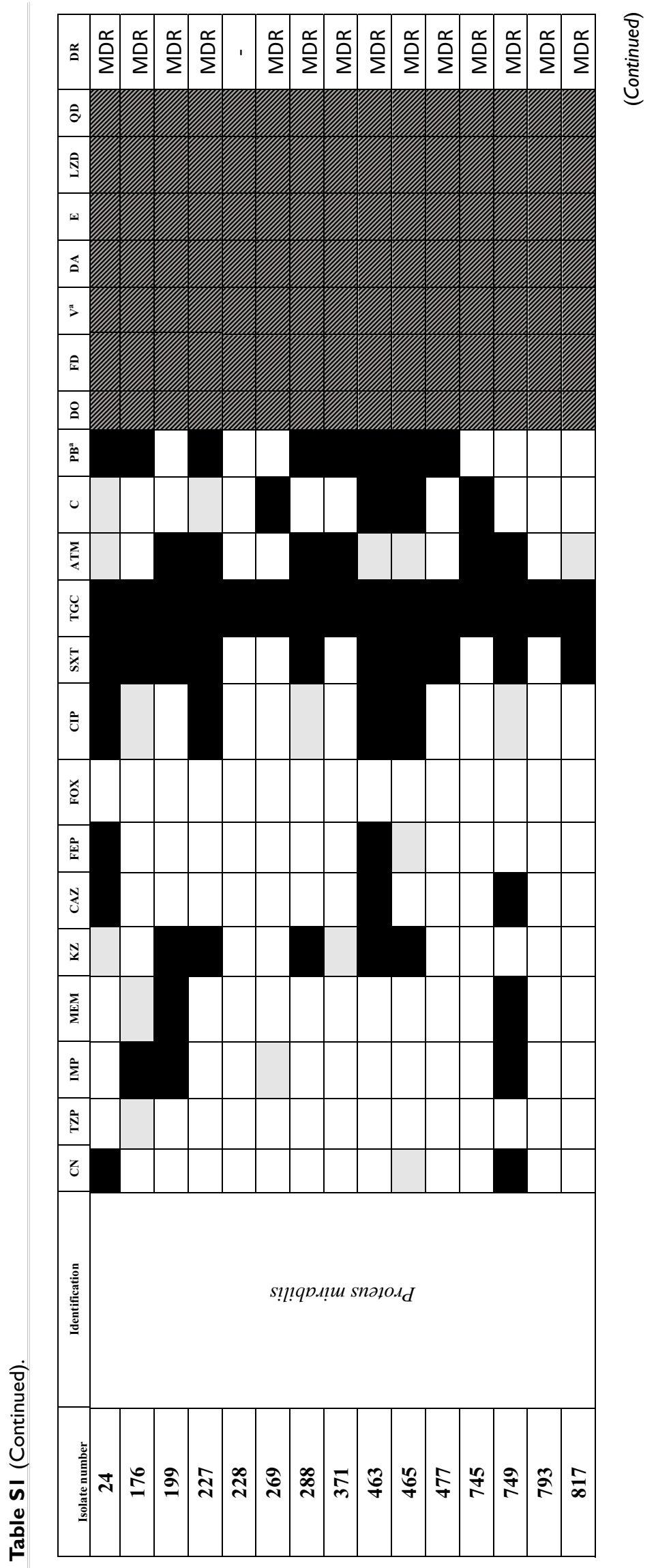




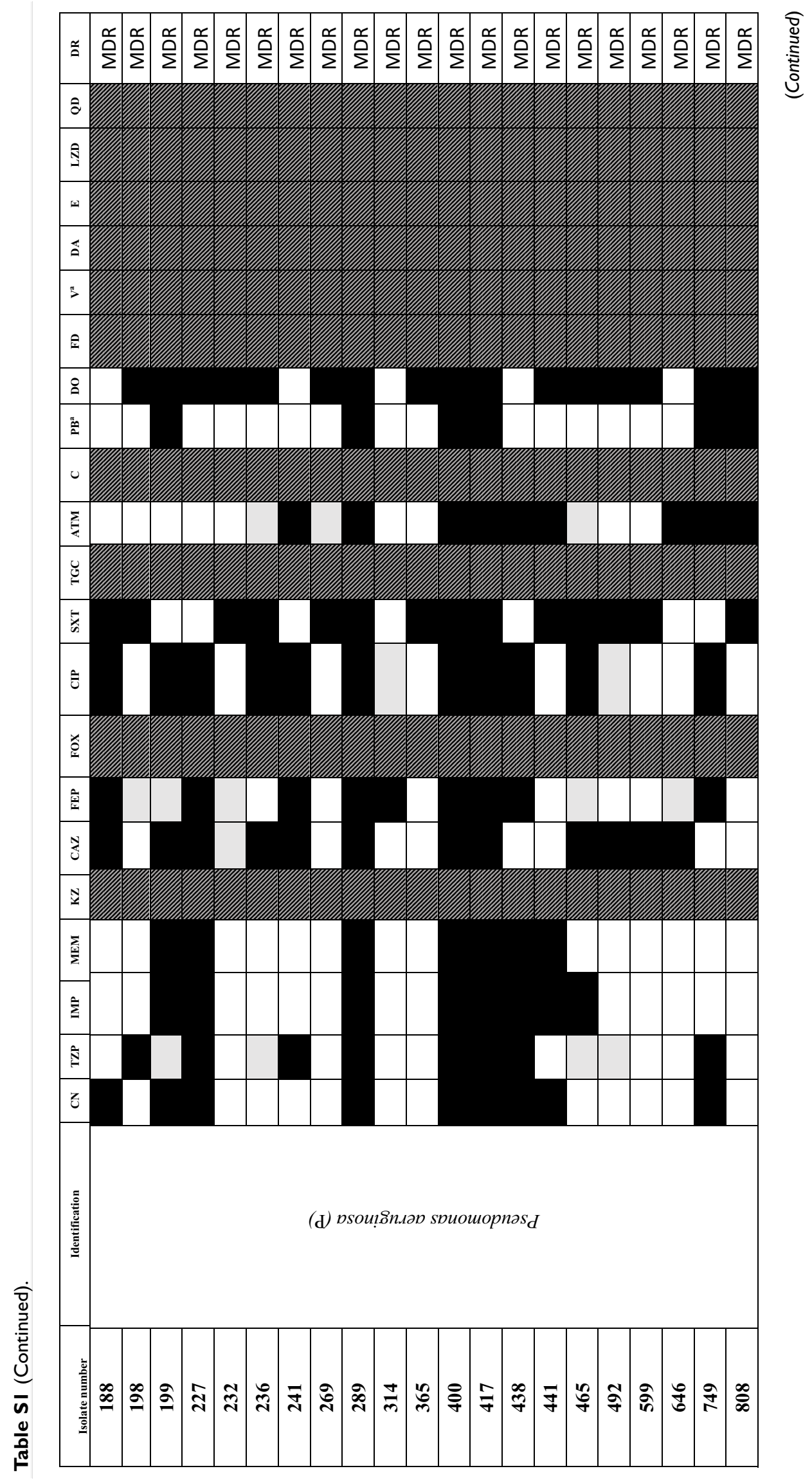




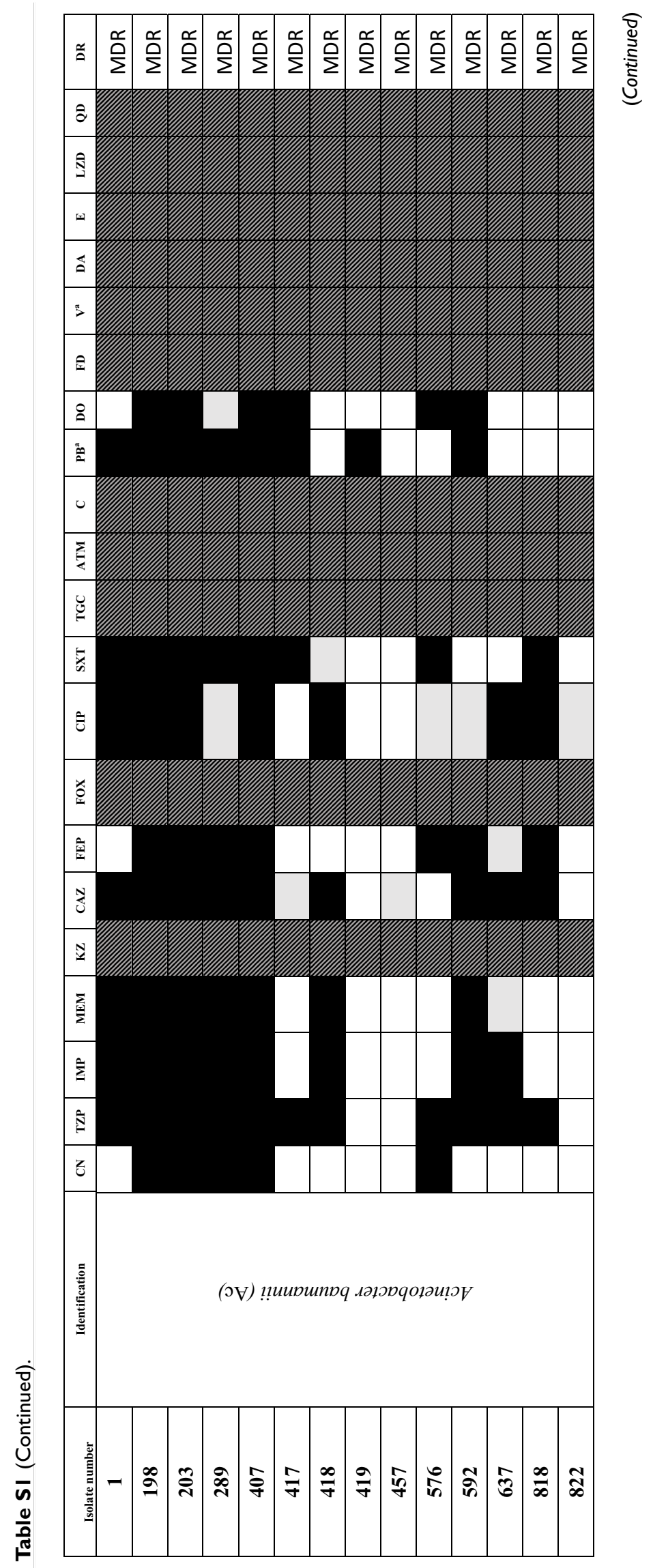




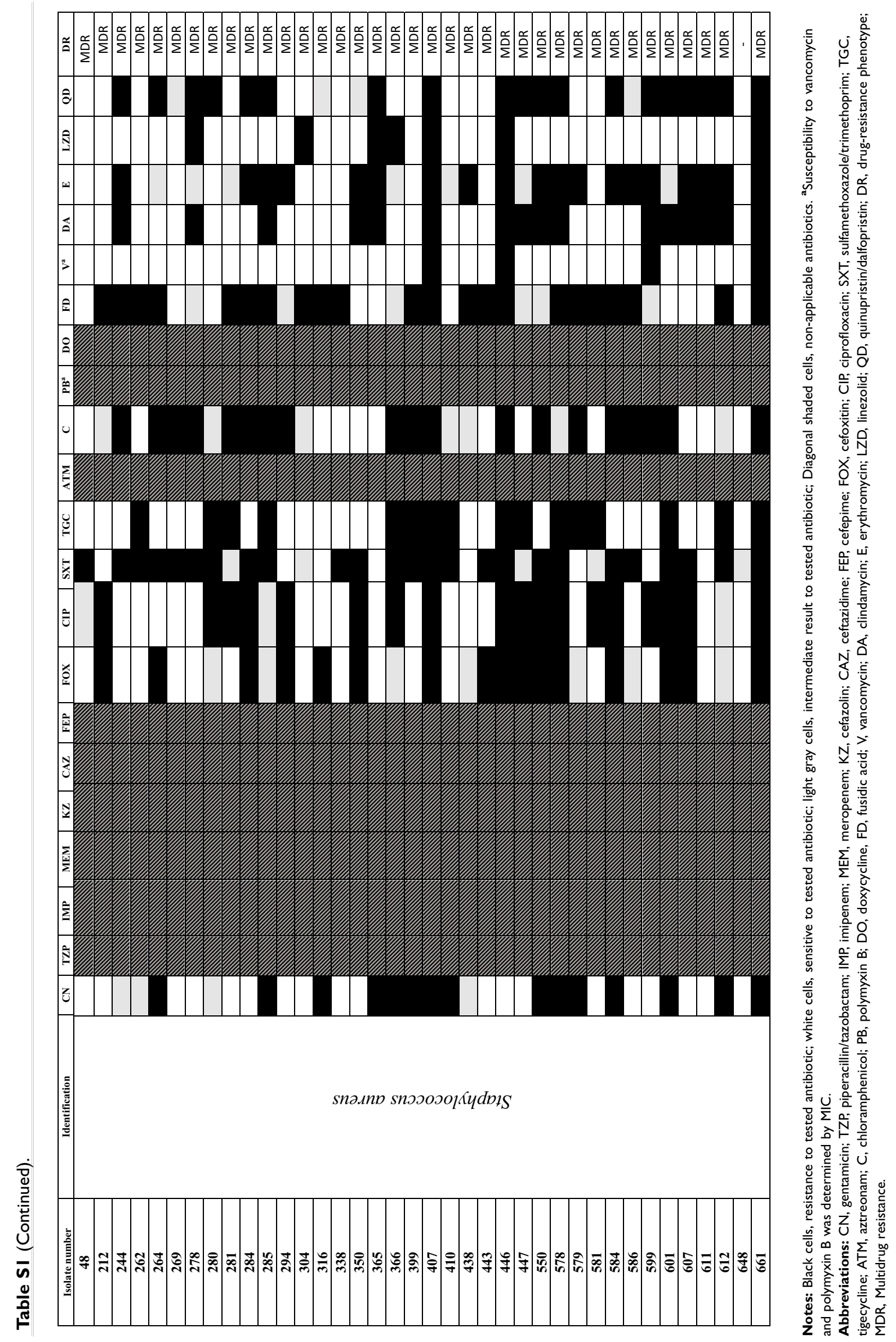




\section{Publish your work in this journal}

Infection and Drug Resistance is an international, peer-reviewed openaccess journal that focuses on the optimal treatment of infection (bacterial, fungal and viral) and the development and institution of preventive strategies to minimize the development and spread of resistance. The journal is specifically concerned with the epidemiology of antibiotic resistance and the mechanisms of resistance development and diffusion in both hospitals and the community. The manuscript management system is completely online and includes a very quick and fair peerreview system, which is all easy to use. Visit http://www.dovepress.com/ testimonials.php to read real quotes from published authors.

Submit your manuscript here: https://www.dovepress.com/infection-and-drug-resistance-journal 